\title{
https://doi.org/10.30853/filnauki.2020.3.23
}

\section{Ли Цзюньин}

Описание национально-культурных единиц: лингвокультурографрический аспект (на примере наименований одежды, обуви и головных уборов)

Статья посвящена сравнительному анализу лингвокультурографических описаний национально-культурных единиц группы "наименования одежды, обуви и головных уборов". Рассматриваются состав и особенности формирования словника, специфичность подачи лингвистических и экстралингвистических сведений. Получены выводы о различии в макро- и микроструктуре справочников, в объеме и характере включенных сведений, о необходимости большей системности и зонирования в презентации энциклопедических данных, привлечения визуальной информации, однотипного описания сходных явлений, экспликации внутригрупповых связей.

Адрес статьи: www.gramota.net/materials/2/2020/3/23.html

\section{Источник}

Филологические науки. Вопросы теории и практики

Тамбов: Грамота, 2020. Том 13. Выпуск 3. С. 111-115. ISSN 1997-2911.

Адрес журнала: www.gramota.net/editions/2.html

Содержание данного номера журнала: www.gramota.net/materials/2/2020/3/

\section{() Издательство "Грамота"}

Информация о возможности публикации статей в журнале размещена на Интернет сайте издательства: www.gramota.net Вопросы, связанные с публикациями научных материалов, редакция просит направлять на адрес: phil@gramota.net 
УДК 81'33

https://doi.org/10.30853/filnauki.2020.3.23

Дата поступления рукописи: 27.01.2020

Статья посвящена сравнительному анализу лингвокультурографических описаний национально-культурных единии группы «наименования одежды, обуви и головных уборов». Рассматриваются состав и особенности формирования словника, специфичность подачи лингвистических и экстралингвистических сведений. Получены выводы о различии в макро- и микроструктуре справочников, в объеме и характере включенных сведений, о необходимости большей системности и зонирования в презентации энциклопедических данных, привлечения визуальной информации, однотипного описания сходных явлений, экспликации внутригрупповых связей.

Ключевые слова и фразы: национально-культурная единица; русский язык; лингвокультурография; лингвокультурологический словарь; лингвистическая информация; экстралингвистическая информация.

\section{Ли Цзюньин}

Казанский (Приволжский) федеральный университет

lijunying@yandex.ru

\section{Описание национально-культурных единиц: лингвокультурографический аспект (на примере наименований одежды, обуви и головных уборов)}

«Синтез филологии и культуры явился мощным фактором актуализации и выделения нового направления... в лексикографии - лингвокультурографии» [9, с. 555]. Формирование этой области словарной науки происходило на рубеже XX-XXI веков [10]. Актуальность данной работы определяется активизацией лингвокультурографической деятельности по созданию лингвокультурологических словарей, появлением новых языковых справочников разнообразного характера, необходимостью комплексного исследования словарного представления национально-культурных единиц сходного и различного типов.

Лингвокультурологический словарь, в котором описываются разнородные национально-культурные единицы, или единицы, обладающие культурной ценностью, включает в себя сведения лингвистического и экстралингвистического (энциклопедического) характера и представляет собой специфический вид омниографического справочника. При этом омниография - это междисциплинарная область, которая занимается теорией и практикой создания справочников разного типа, как содержащих сугубо лингвистические или энциклопедические сведения, так и объединяющих эти виды информации в различных сочетаниях. Соответственно, языковыми справочниками занимается лингвография, а энциклопедическими - денотатография [6, с. 8-9], а лингвокультурография является особой областью омниографии. Лингвокультурологические словари отличаются объемом и соотношением представленной в них языковой и внеязыковой информации, подходами к регистрации и описанию включенных единиц (нередко и в сходных по многим параметрам справочниках). Это обстоятельство обуславливает целесообразность разностороннего исследования справочников этого типа, их информационного обеспечения.

Научная новизна настоящей работы состоит в том, что в статье впервые приводится исследование лингвистической и экстралингвистической информативности лингвокультурографических источников при описании единиц с культурной ценностью, принадлежащих к одной тематической группе.

Работа посвящена анализу единиц тематической группы «наименования одежды, обуви и головных уборов» в восьми современных словарях лингвокультурологического характера. Целью нашей работы является сравнительное исследование словарных описаний единиц, относящихся к данной группе, в плане макро- и микроструктуры, а также выявление общих и специфических характеристик и материалов в статьях как разных справочников, так и отдельно взятого словаря. Указанные цели предусматривают решение ряда задач: а) анализ состава данной тематической группы в исследуемых справочниках; б) изучение формы словарного представления описываемых единиц и их характеристик; в) раскрытие содержания и формы подачи лингвистической и экстралингвистической информации в анализируемых источниках; г) выявление общих и специфических черт лингвокультурографических описаний рассматриваемых единиц, а также недостатков и недочётов в этих описаниях.

В исследовании проводится интер- и интрасловарный анализ лингвокультурографических описаний с использованием сравнительного и количественного методов.

Результаты и материалы исследования будут использованы в рамках сводного фонда русских словарей лингвокультурологического типа, который формируется на кафедре прикладной и экспериментальной лингвистики Казанского федерального университета и в котором будут представлены материалы как одноязычных, так и двуязычных словарей [5], а также могут быть применимы в процессе анализа и совершенствования существующих, а также создания и редактирования новых лингвокультурографических описаний единиц как данной, так и других тематических групп. 
Анализируемые словари представляют собой справочники учебного типа и относятся (по мнению авторов) к различным типам:

а) лингвострановедческим (ЛСС): «Россия. Большой лингвострановедческий словарь» (далее ЛСС_Россия);

б) лингвокультурологическим (ЛКС): «Ключ к русской культуре: словарь лингвокультурной грамотности» (далее - ЛКС_Анс.); «Лингвокультурологический словарь для школьников» (далее - ЛКС_Дав.); Г. Ш. Кузьмина «Лингвокультурологический словарь-комментарий к произведениям С. Т. Аксакова» (далее ЛКС_Куз.); «Реалии русской культуры. Лингвокультурологический словарь» (далее - ЛКС_Мул.);

в) культурологическим (КС): «Словарь культуроведческой лексики русской классической литературы» (далее - КС_Бир.); «Русская история и культура в художественном слове. Словарь» (далее - КС_Кур.); «Культурологический словарик русского языка: читаю книги по-настоящему» (далее - КС_шк_Бир.).

Словари отличаются структурой, порядком расположения материала:

1) алфавитные словари - 4 (КС_Бир., КС_шк_Бир., КС_Кур., ЛСС_Россия);

2) тематические словари:

a) с алфавитным указателем - 3 (ЛКС_Анс., ЛКС_Куз., ЛКС_Мул.);

б) без алфавитного указателя - 1 (ЛКС_Дав.).

Среди лингвокультурологических словарей дидактической направленности более информативным представляется тематический справочник, единицы в котором группируются с учетом не формальных признаков (близость буквенного состава), а содержательных (тематическая близость). Тематический словарь становится более удобным для пользователя, если он дополняется алфавитным указателем (см. группу 2a).

Для алфавитных словарей экспликации содержательных связей слов могут способствовать тематические указатели, а также перекрестные отсылки к тематически близким единицам (например: шуба $c p$. тулуп).

Как показывает межсловарный и внутрисловарный сравнительный анализ, рассматриваемые справочники отличаются объемом и составом включенных единиц, особенностями их представления. Словарные статьи анализируемых словарей содержат информацию двух основных типов - языковую (лингвистическую) и экстралингвистическую (энциклопедическую, историко-культурную). Соотношение этих сведений различно в соответствующих статьях а) как разных словарей, б) так и одного источника. Это объясняется различиями в концепциях словарей, в установках их авторов (например, в отношении адресата), в характере описываемых единиц (в ситуациях а) и б)); в ряде случаев - упущениями в словарных описаниях, в частности, разнотипной подачей и интерпретацией сходных единиц (в ситуации б)).

Сходные единицы, обладающие одинаковыми признаками и характеристиками, входящие в один омниографический (лингвографический, денотатографический) класс, должны в «справочниках описываться одинаковым образом». Хотя эта мысль «достаточно очевидна, однако ошибки, связанные с этим, встречаются... довольно часто» $[6$, с. 66]. Требование однотипного описания единиц одного класса относится как к макроструктуре (включение/невключение единиц в состав словника), так и к микроструктуре, к словарной статье (объём и характер подачи и описания лингвистической и экстралингвистической (энциклопедической, культурной) информации).

В анализируемых источниках количество единиц в группе «наименования одежды, обуви и головных уборов» различается: 7 слов в ЛСС_Россия и ЛКС_Анс., 79 - в КС_Кур.; ЛКС_Мул. - 17 слов; ЛКС_Дав. - 22; ЛКС_Куз.-23; КС_шк_Бир. - 32; КС_Бир. - 43.

Статьи одних и тех же слов в разных словарях нередко существенно отличаются объемом; ср., например, статьи кафтан в двух лингвокультурологических словарях: в ЛКС_Дав. статья содержит всего 89 слов, а в ЛКС_Куз. - 652 слова. Это в значительной степени объясняется различием установок авторов словарей относительно включаемой информации. Нередки случаи, когда в одном источнике единицы, относящиеся к одной группе, имеют разные по объему и характеру описания; см., например, названия головных уборов в ЛКС_Дав.: словарная статья картуз занимает 6 столбцов, а кика (кичка) - 18 столбцов. В ЛКС_Мул. душегрейка, армяк - 2 абзаца, сарафан - 9 абзацев, кафтан - 10, рубаха - 12, шуба - 13 абзацев.

Форма представления материала в анализируемых словарях характеризуется разнообразием: например, статья в ЛСС_Россия представлена в виде единого текста, границы зон не выделяются; в ЛКС_Анс. все материалы размещены строго по зонам, вводимым специальными знаками, см. статью кафтан:

КАФТАН

^ Старинная мужская одежда.

- «Тришкин кафтан»- басня И. А. Крылова, название которой стало означать непрофессиональное устранение одних проблем за счёт появления других.

:: Тришкин, кушак, тепло.

通 Верхняя распашная одежда свободного кроя русского национального мужского костюма горожанина. Расшивали их по-разному - в зависимости от статуса и уровня достатка.

Крестьяне носили зипуны и армяки.

$\checkmark$ Узоры на кафтане, как и на другой одежде, считались оберегом, защчищающим человека от негативного воздействия враждебного мира, нечистой сильl, дурного глаза [1, с. 91-92].

Подобные различия в объеме и форме подачи усиливают актуальность и необходимость анализа информационного наполнения словарных статей однородных (сходных) единиц в рамках как одного словаря, так и группы однотипных словарей. В процессе анализа выявлены различия и недочёты представления сходных слов в словарях лингвокультурологического типа. 
Проведённый анализ содержащейся в словарях лингвистической и экстралингвистической информации позволяет отметить следующее.

Различие лингвистического описания единиц сходного типа в составе анализируемых источников

I. Особенности описания и представления материала в разных словарях:

1. Использование разных форм заголовочных единиц. Например, в большинстве словарей представлена заголовочная единица лапти, кроме КС_шк_Бир., где указана форма лапоть. Хотя слово чувяки в этом же словаре представлено в форме множественного числа с указанием «обычно мн.» [3, с. 181].

2. Отсутствие базовой лингвистической информации:

a) ударение не представлено в ряде анализируемых словарей учебного характера. Например, в словарях ЛКС_Анс., предназначенном для иностранных студентов, и ЛКС_Дав. - для школьников и студентов;

б) морфологическая (частеречная, словоизменительная) информация не содержится в словарях ЛСС_Россия, ЛКС_Анс., ЛКС_Мул. и ЛКС_Дав.

В словарях дидактической направленности нецелесообразно отказываться от включения этой минимальной лингвистической информации, необходимой для пользователей этих справочников.

3. Различия в подаче и описании включенных слов отражаются, например:

а) в трактовке тех или иных лексических единиц и групп; нередко одни те же слова в разных словарях описываются по-разному. В словаре КС_Кур. отмечены устаревшие слова, среди них отсутствует слово душегрейка, которое в других словарях (см. КС_Кур. и КС_шк._Бир.) обозначено как устаревшее. Аналогичная ситуация также и с подачей в источниках слова лапти (лапоть);

б) в подаче этимологической информации. В некоторых словарях содержатся указания на заимствованный характер рассматриваемых единиц. В других словарях отсутствуют такого рода сведения. Например, для слова кафтан в словарях ЛКС_Мул. и ЛКС_Куз. содержится информация о происхождении его из тюркских языков; для лексемы сарафан в ряде словарей сообщается о заимствовании её из персидского языка, а в КС_Кур. для указанных слов не приводятся такие сведения. Хотя в КС_Кур. этимологические справки представлены для других единиц данной группы; см., например: бекеша œ из польск. bekiesza венг. Bekes [8, с. 24].

Указанные различия объясняются разными подходами к определению лингвокультурографической ценности некоторых видов языковой информации или являются упущениями в словарном представлении данных видов сведений в статьях.

II. Особенности описания и представления материала в рамках одного лингвокультурографического источника. Здесь в первую очередь следует указать на разнотипное представление сходных материалов:

1. Словообразовательные особенности описываемых слов; например, в ЛКС_Мул., ЛКС_Куз. соответствующие сведения присутствуют лишь у отдельных слов. В ЛКС_Мул. только у слов башльк и лапти есть сведения о том, от каких слов они образованы, см. башлькк: суф. производное от баш - «голова» [11, с. 81]; лапти: обычно объясняется как суф. производное (ср. ноготь и т.п.) от той же основы, что лапа. Возможно, однако, что это слово является суф. производным от лапь «тряпка, заплатка» [Там же, с. 82-83]. В ЛКС_Куз. словообразовательная информация представлена только у 4 (из 23) слов (камзол, мундир, тюбетейка, чепеи); см. чепец (чепчик): <...> Образовано с помощью суф. -ьиь (совр. -ец) от основы чеп-, восходящей к *кер и родственной основе в лит. kериге - «шапка», греч. skepas - «покрывало» [7, с. 117].

2. Раскрытие содержания описываемой единицы; например, толкования в ЛКС_Дав. отличаются объемом и характером. Для части слов, имеющих культурную ценность, дается очень краткое толкование, которое не в полной мере раскрывает семантическое наполнение лексем, а также их культурную составляющую; ср.:

сарафан - род платья без рукавов [4, с. 114];

кафтан - кафтан - длинная тёплая одежда из чёрного серого или синего домашнего сукна (далее идёт описание формы, предназначения и материала разных видов кафтана) [Там же, с. 110];

кушак - длинный узкий шерстяной, шелковый или суконный мужской пояс, которым подпоясывались поверх рубахи, кафтана, иубы и т.д. [Там же, с. 112].

3. Этимологическая характеристика описываемых слов; например, в ЛСС_Россия указаны происхождения всех анализируемых единиц, кроме слова рубаха. В ЛКС Мул. этимологические сведения представлены в 17 словарных статьях, отсутствуют у 6 слов. Местонахождение материалов данного параметра в ЛКС_Мул. у разных лексем различно: у отдельных слов - в начале статьи сразу после заголовочной единицы; см.: сарафан - от перс. серапа - почётная одежда (далее идет толкование); а у остальных слов - внутри статей.

\section{Различие экстралингвистического описания единиц сходного типа в составе анализируемых источников}

В процессе анализа словарных статьей слов, относящихся к группе «одежда, обувь и головные уборы», выявлены разнохарактерные экстралингвистические сведения, представленные в разных объемах и формах. Особенности лингвокультурографического описания в ЛСС_Россия, ЛКС_Мул., ЛКС_Куз. заключаются: а) в представлении наряду с лингвистическими сведениями в рамках единого текста статьи; б) в презентации в объёмной и развёрнутой форме. Для ряда справочников характерно выделение специальной зоны в статье (см. зону «УЗНАЙ БОЛЬШЕ!» в КС_шк._Бир.).

В ЛСС_Россия авторы предлагают страноведческую (культурную) и лингвострановедческую информацию. Страноведческая (культуроведческая) информация представляет собой краткую энциклопедическую справку, 
которая содержит информацию о месте и значении данной реалии в истории и культуре России [12, с. 2]. Лингвострановедческая зона представляет собой описание национально-культурного фона заголовочного слова. В этой зоне раскрываются ассоциативные и символизирующие сведения о национальных реалиях, обозначенных заголовочной единицей; оценочная информация различных исторических периодов и т.д. [Там же]. Отличия описаний - в объеме, способе и содержании описания, например, лингвострановедческая зона занимает у слов данной группы от 20 до более 90 столбцов. Разный объем объясняется различным характером включенной в словарные статьи информации. В статьях рубаха, шапка, сарафан и шуба представлены более развернутые описания, включающие различные сведения: а) типы описываемых предметов, состав материала, украшения, технология изготовления и др.; б) изменение предмета, употребление его раньше и в современной жизни; в) связь с традициями, обычаями и т.д.

В словаре представлены фразеологизмы, устойчивые выражения, паремии (пословицы, поговорки), ссылки на известные произведения литературы и искусства, народные песни, сказки и т.д. (см. статьи рубаха, шапка, шуба), они формируют национально-культурный фон описываемых слов, относятся к лингвострановедческой зоне; см. валенки: Одна из известных русских народных песен так и называется «Валенки» [Там же, с. 85], описание такого рода встречается также у слов лапти, сарафан.

Развернутая характеристика представлена в ЛКС_Мул. для части слов, см. шуба, рубаха, кафтан, сарафан и т.д. Энциклопедическое описание лексических единиц, относящихся к группе «одежда», заключается в представлении: а) происхождения, развития, изменения описываемой реалии в истории, а также в разных регионах; б) формы, состава данного предмета; в) роли предмета в жизни.

В статьях слов, относящихся к подгруппе «головой убор», представлена (кроме исторических сведений) информация о символике реалии; см. фата: В русском быту фата была символом непорочности и чистоты девушки, поэтому в свадебном обряде голова невесты покрывалась белой фатой (дальше идет информация о разных фатах, которые носят женщины) [11, с. 82]. В отдельных статьях представлена информация об отражении реалии (образа) в фольклорных произведениях; см. сапоги: В русских сказах часто волшебными помощзниками героя оказываются сапоги-самоходы, которые уносят путника, как ковёр-самолёт [Там же, с. 83].

К сожалению, для части единиц в этой группе не приводится информация национально-культурного характера, см. армяк, кокошник, шаль.

Основным компонентом в словарных статьях ЛКС_Куз. является историко-энциклопедическое описание, которое представляет сведения о появлении, изменении одежды, головного убора, об их изготовлении, видах и др. Например, в статье сарафан наряду с энциклопедическим толкованием описаны: а) прохождение сарафана; б) время, когда сарафан появился в русских письменных источниках (XIV в.); в) время, когда $c a-$ рафан стал обозначением женской одежды (XVII в.); г) эволюция сарафана с XVII по XX вв. и его роль в жизни людей разных общественных слоев.

Историко-энциклопедическая информация встречается во всех словарных статьях (кроме шальвары, рубище).

В ЛКС_Анс. выделяются три особые зоны, которые отражают лингвокультурную информацию: зона распространенных ассоциаций (*), зона «минимальная справочная информация» ( 通) и «дополнительная информация» $(\boldsymbol{V})$. С учетом характера представленной здесь информации остановимся на указанных зонах подробнее.

В зоне распространенных ассоциаций (:0) перечисляются слова или словосочетания, вызванные ассоциациями заглавной единицы; см. сарафан : Красный, лето, кафтан, девушка, ситиевый [1, с. 100]. Зона представлена во всех анализируемых словарных статьях.

Зона «минимальная справочная информация» представляет собой:

а) более развернутое энциклопедическое описание о слове; см. сарафан Элемент северно-русского костюма. Отличается сочетанием простоты силуэта и богатства отделки, яркими иветами, прямыми линиями и многослойностью. Сарафан одевался поверх рубахи, а поверху него - душегрея и передник (фартук). В южных районах России вместо сарафана одевалась понёва - клетчатая юбка. На свадьбу чаще всего надевали красныле сарафаньл [Там же];

б) историко-описательные справки, см. телогрейка: Куртка из хлопка и ваты. Телогрейки появились еще в Российской империи, но именно в советский период в них увидели одежду, которая подходит и для рабоmbl, и для войны [Там же, с. 115].

Зона «дополнительная информация» $(\boldsymbol{V})$ включает в себя разнородные сведения:

а) информация, связанная с предметом, актуальная в современной жизни, см. валенки: Музеи валенок есть в Москве, Мышкине и Кинешме [Там же, с. 88];

б) культурные признаки, передающиеся реалией, см. кафтан, сарафан;

в) энциклопедическая информация, см. лапти, телогрейка;

г) информация, которая напрямую не относится к описываемой реалии; см. в статье лапти его омоним: лапоть - старинная мера длины [Там же, с. 95-96].

Описываемые единицы содержат один или несколько из вышеуказанных видов информации; так, в статье сарафан представлены: культурные признаки, которыми обладает сарафан, виды сарафана, значение сарафана в современном обществе, песня о сарафане, соответствующие головные уборы с разными сарафанами и др. Строгое, зонное представление различных сведений энциклопедического характера является сильной стороной данного словаря.

Историко-культурная информация в остальных словарях присутствует только у отдельных слов. 
В ЛКС_Дав. энциклопедическая (культурная) информация представлена вместе с толкованием у слов кафтан, кика (кичка), кокошник, лапти, повойник, салоп.

В КС_шк_Бир. информация исторического характера предлагается в статьях казакин, камзол, халат; в статьях кафтан, лапти приведены историко-культурные описания, а также пословицы, поговорки, загадки, связанные с этими словами.

В КС_Бир. историко-культурное описание содержится у 8 слов (из 42 слов), для отдельных слов указаны ассоциации, символы или их отражения в литературе, см. венеи, боливар.

В КС_Кур. в зоне дополнительных сведений у 8 описываемых слов (среди 79 слов) содержится следующая информация: обряд, традиция, связанная с заголовочной единицей, см. волюшка, чепец; историкоэнциклопедическое описание, см. кафтан, салоп, шушун; история реалии, см. панталоны; культурные признаки, символы, воплощенные описываемыми словами, см. сарафан, халат.

В результате анализа выявились проблемы, связанные с формированием словников справочников лингвокультурологического типа - такие, как состав объектов описания, вопросы включения/невключения слов в словарь, с характером и объемом описания соответствующих единиц в рамках словарей, в частности, единообразие/неединообразие лингвокультурографического представления сходных наименований и др.

Анализируемые источники, сущностным признаком которых является наличие языковой и культурной информации, имеют особенности в плане 1) макроструктуры - отличаются составом группы «наименования одежды, обуви и головных уборов» (от 7 до 79 единиц), расположением описываемых единиц в источнике (алфавитное, тематическое, а также сочетающее в себе черты предыдущих двух, последний тип следует признать наиболее оптимальным для учебных лингвокультурологических словарей); 2) микроструктуры - отличаются содержанием, степенью структурированности и соотношением включаемых лингвистических и экстралингвистических сведений (наличие/отсутствие а) языковых и б) внеязыковых данных, в) использование/ неиспользование зонной формы презентации разных видов историко-культурной информации, а также визуальной наглядности).

Как показывает анализ, росту информативности исследуемых словарей в значительной степени способствуют усиление системности отбора и описания лингвокультурологического материала, строго зонное представление сведений (особенно энциклопедических), расширенное отображение различных связей описываемых единиц в рамках тематических объединений.

\title{
Список источников
}

1. Ансимова О. К. Ключ к русской культуре: словарь лингвокультурной грамотности. Новосибирск: Изд-во НГТУ, 2016. $222 \mathrm{c}$.

2. Бирюкова С. К. Словарь культуроведческой лексики русской классической литературы. СПб.: Просвещение, 2005.350 с.

3. Бирюкова С. К., Андреева И. В. Культурологический словарик русского языка: читаю книги по-настоящему: пособие для учащихся начальной школы. М.: Дрофа, 2008. 207 с.

4. Давлетбаева Р. Г. Лингвокультурологический словарь для школьников. Диалог языков и культур. Уфа: Китап, 2003. 160 с.

5. Каримуллина Р. Н., Ли Цзюньин. Русско-китайские словари: формирование словника // Филология и культура. 2019. № 3 (57). C. 52-57.

6. Компьютерная лингвография / под ред. Н. К. Замова, К. Р. Галиуллина. Казань: Изд-во Казанского ун-та, 1995.119 с.

7. Кузьмина Г. Ш. «И образ мира, в слове явленный...»: лингвокультурологический словарь-комментарий к произведениям С. Т. Аксакова / под ред. Л. Г. Саяховой. Уфа: РИО РУНМЦ МО РБ, 2004. 302 с.

8. Курносова И. М. Русская история и культура в художественном слове. Словарь: учеб. пособие. М.: Высшая школа, $2010.380 \mathrm{c}$.

9. Лексикография русского языка / под ред. Д. М. Поцепни. СПб.: Филол. фак-т СПбГУ, 2013. 704 с.

10. Лукьянова Н. А. Лингвокультурография в системе современной российской лексикографии (90-е гг. XX - начало XXI в.) // Тexne grammatike (Искусство грамматики). 2006. Вып. 2. С. 303-326.

11. Муллагалиева Л. К. Реалии русской культуры. Лингвокультурологический словарь: учебное пособие для средних школ и учителей русского языка. Уфа: Изд-во БИРО, 2001. 220 с.

12. Россия. Большой лингвострановедческий словарь / под общ. ред. Ю. Е. Прохорова. М.: АСТ-Пресс Книга, 2007.736 с.

\section{Description of Culturally Specific Units: Linguo-Culturographical Aspect (by the Example of Clothes, Footwear and Hat Names)}

\author{
Li Junying \\ Kazan (Volga Region) Federal University \\ lijunying@yandex.ru
}

The article provides a comparative analysis of linguo-culturographical descriptions of culturally specific units of the lexicosemantic group "clothes, footwear and hat names". The author examines dictionaries structure and peculiarities of their formation, identifies specificity of presenting linguistic and extra-linguistic information. The conclusions are made about differences in dictionaries macro- and micro-structure, in the amount and nature of included information. The researcher justifies reasonability of a more systemic approach to encyclopaedic data presentation, emphasizes the necessity to provide visual information, to present a unified description of similar phenomena, to explicate intra-group relations.

Key words and phrases: culturally specific unit; Russian language; linguo-culturography; linguo-culturological dictionary; linguistic information; extra-linguistic information. 